\title{
USO DE GEOTECNOLOGIAS PARA ANÁLISE AMBIENTAL DA BACIA HIDROGRÁFICA DO CÓRREGO SANTA FÉ
}

\author{
Suzane Ferreira de Lima ${ }^{1}$ \\ Thiago de Andrade Águas ${ }^{2}$ \\ Karen Cristina Pereira Costa ${ }^{3}$
}

\begin{abstract}
RESUMO
As pressões exercidas sobre o ambiente natural vêm transformando de modo desordenado suas paisagens. Deste modo, o conceito de planejamento ambiental tem sido discutido, visando minimizar esses impactos e criando diretrizes para sua gestão continuada. Pretende-se definir índices de vulnerabilidade para a região com o suporte de mapas temáticos, evidenciando as características ambientais na área da Bacia Hidrográfica do córrego Santa Fé, situada no município de Aparecida do Taboado/MS. O município encontra-se na porção leste do Estado de Mato Grosso do Sul e se localiza entres os paralelos $20^{\circ} 4^{\prime} 41.51^{\prime \prime}$ e $20^{\circ} 9^{\prime} 0.82^{\prime \prime}$ de latitude $S$ e os meridianos $51^{\circ} 77^{\prime} 29.65^{\prime \prime}$ e $51^{\circ}$ 8'47.99"de longitude W. Foram utilizadas imagens de satélite e a coleta de dados primários e secundários da área para produzir mapas de análise da declividade, pluviosidade, tipos de solos, áreas prioritárias e uso da terra, que integrados resultaram em um mapa de vulnerabilidade da Bacia do Córrego Santa Fé. A análise proposta possibilitou elaborar um mapa integrado com os dados naturais da área, assim como subsídio para destacar a forma que a bacia vem sendo degradada com seu uso intensivo, demonstrando suas fragilidades e potencialidades.
\end{abstract}

PALAVRAS - CHAVE: Bacia Hidrográfica, Vulnerabilidade Ambiental e Geoprocessamento.

\section{GEOTECHNOLOGY USE FOR ENVIRONMENTAL ANALYSIS OF THE RIVER OF SANTA FÉ STREAM BASIN}

\begin{abstract}
The pressures on the natural environment have transformed a disorderly manner his landscapes. Thus, the concept of environmental planning has been discussed to minimize these impacts and creating guidelines for its ongoing management. It is intended to define vulnerability indices for the region with the support of thematic maps, showing the environmental characteristics in the area of Watershed Stream Santa Fe, located in the city of Aparecida do Taboado-MS. The city is in the eastern portion of the State of Mato Grosso do Sul and is located entres the parallels $20{ }^{\circ} 4^{\prime} 41.51^{\prime \prime}$ and $20^{\circ} 9^{\prime} 0.82$ "S latitude and meridians $51^{\circ} 7^{\prime 2} 29.65^{\prime \prime}$ and 51 8'47.99 "W. longitude were used satellite images and collecting primary and secondary data analysis of the area to produce maps of slope, rainfall, soil types, priority areas and land use, which resulted in an integrated map Vulnerability Basin Stream Santa Fe. The proposed analysis enabled prepare an integrated map with the natural data of the area, as well as a subsidy to highlight how the basin is being degraded with their intensive use, showing its weaknesses and strengths.
\end{abstract}

KEY WORDS: Hydrographic Basin, Environmental Vulnerability and Geoprocessing.

\footnotetext{
1 Geógrafo, mestrando em Geografia pelo PPGGEO/UFMS. suzy nh@hotmail.com

2 Mestre em Geografia pelo PPGGEO/UFMS. thdeandrade@gmail.com

${ }^{3}$ Graduanda em Geografia Licenciatura pela UFMS/CPTL. karen_cpcosta@hotmail.com.
} 


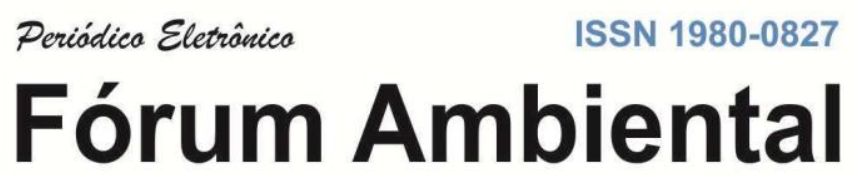

da Alta Paulista

\title{
USO GEOTECNOLOGÍA PARA ANÁLISIS AMBIENTAL DEL RÍO DE SANTA FÉ ARROYO CUENCA
}

\begin{abstract}
RESUMO
Las presiones sobre el medio natural han transformado de manera desordenada sus paisajes. Por lo tanto, el concepto de planificación ambiental se ha discutido para minimizar estos impactos y directrices creando para su gestión en curso. Se pretende definir índices de vulnerabilidad para la región con el apoyo de mapas temáticos, que muestra las características ambientales de la zona de Arroyo de la Cuenca Santa Fe, ubicada en la ciudad de Aparecida do Taboado / MS. La ciudad se encuentra en la parte oriental del Estado de Mato Grosso do Sul y se encuentra entres los paralelos $20^{\circ} 4^{\prime} 41.51$ "y $20^{\circ} 9^{\prime} 0.82$ " S de latitud y $51^{\circ} 7^{\prime} 29.65$ "meridianos y $51 \circ 8$ '47.99 'W. longitud se utilizaron imágenes de satélite y la recolección de análisis de datos primarios y secundarios de la zona para producir mapas de pendiente, precipitaciones, tipos de suelo, las áreas prioritarias y uso de la tierra, lo que resultó en un mapa integrado Vulnerabilidad Corriente Cuenca del Santa Fe. El análisis propuesto permitió elaborar un mapa integrado con los datos naturales de la zona, así como un subsidio para destacar cómo se está degradando la cuenca con su uso intensivo, mostrando sus debilidades y fortalezas.
\end{abstract}

PALABRAS CLAVE: Cuenca, Vulnerabilidad Ambiental y Geoprocesamiento.

\section{INTRODUÇÃO}

Para fins de planejamento ambiental, Santos (2004) ressalta a importância do estudo de bacias hidrográficas, onde as mesmas se caracterizam como unidades de planejamento de aceitação universal. É uma unidade onde os fenômenos de interação podem ser entendidos facilmente, pois são unidades geográficas onde os recursos naturais se integram.

Nesse sentido o enfoque geográfico referente ao estudo da natureza transcorre da conexão de diversos elementos, e direciona seus enfoques para as questões processuais e interventoras da sociedade e os efeitos impactantes derivados dessas intervenções no meio natural. Segundo Freire (2011), no que se refere aos reflexos das diversas ações impostas ao ambiente torna-se necessário considerar as características ligadas à fragilidade e vulnerabilidade de tais espaços.

Estes estudos referentes às fragilidades dos ambientes são de extrema importância ao Planejamento Ambiental, à identificação dos ambientes naturais e suas fragilidades potenciais e emergentes proporcionam uma melhor definição das diretrizes e ações a serem implementadas no espaço físico-territorial, servindo de base para o zoneamento e fornecendo subsídios à gestão do território.

De acordo com Ross (1994), as unidades de fragilidade dos ambientes naturais devem ser resultantes dos levantamentos básicos de geomorfologia, solos, cobertura vegetal/uso da terra e clima e por fim, para análise da fragilidade exige-se que esses conhecimentos setorizados sejam avaliados de forma integrada, sempre 
no princípio de que a natureza apresenta funcionalidade inseparável entre seus componentes físicos e bióticos. Podendo ser aplicado, desta maneira, ao planejamento territorial ambiental.

Segundo Crepani (2001), para que se analise uma unidade de paisagem natural é necessário que se conheça sua gênese, constituição física, forma e estágio de evolução, bem como a natureza de sua cobertura.

Conforme Camargo (1997) para estudar questões que envolvem diversas variáveis, como é o caso do estudo de bacias hidrográficas assim como para elaboração de trabalhos relacionados à fragilidade ambiental, o SIG apresenta-se como um moderno instrumento para o planejamento, controle e supervisão.

Através do desenvolvimento dos SIGs, as ferramentas de geoprocessamento vêm sendo muito utilizado em trabalhos relacionados a dados espaciais, pois possibilita a extração de informações sobre a bacia e sua organização, permitindo estudos relacionados aos recursos hídricos.

Segundo Ferreira (2011) apud Mirandola-Avelino (2006) em um país como o Brasil, que possui uma grande carência de informações adequadas para a tomada de decisões sobre os problemas urbanos, rurais e ambientais, o geoprocessamento apresenta um enorme potencial, principalmente se baseado em tecnologias de custo relativamente baixo, em que o conhecimento seja adquirido localmente.

\section{OBJETIVOS}

A aplicação das geotecnologias se apresenta como uma ferramenta de ordem geográfica destinada a mapeamentos das transformações do uso e cobertura vegetal e da fragilidade ambiental potencial, principalmente em estudos de bacias hidrográficas, servindo como um instrumento de planejamento e gestão do território. (BACANI, 2010)

Portanto, o presente trabalho tem como objetivo geral gerar e analisar os mapas de Potencial Ambiental e Fragilidade Ambiental da Bacia Hidrográfica do Córrego Santa Fé, possibilitando desta forma sua utilização no planejamento com finalidade de manejo, prevenção e recuperação da área em potencial. 


\section{LOCALIZAÇÃO}

A bacia hidrográfica Córrego Santa Fé está totalmente inserida nos limites municipais de Aparecida do Taboado MS, sendo um dos afluentes do rio Quitéria que por vez deságua no rio Paraná, situado entre os paralelos $20^{\circ} 04^{\prime} 41.51$ "S e $20^{\circ} 09^{\prime} 0.82^{\prime \prime} \mathrm{S}$ e meridianos $51^{\circ} 07^{\prime} 29.65^{\prime \prime O}$ e 510.'47.99"O (Figura 1).

Figura 1: Mapa de localização da Bacia Hidrográfica do Córrego Santa Fé.

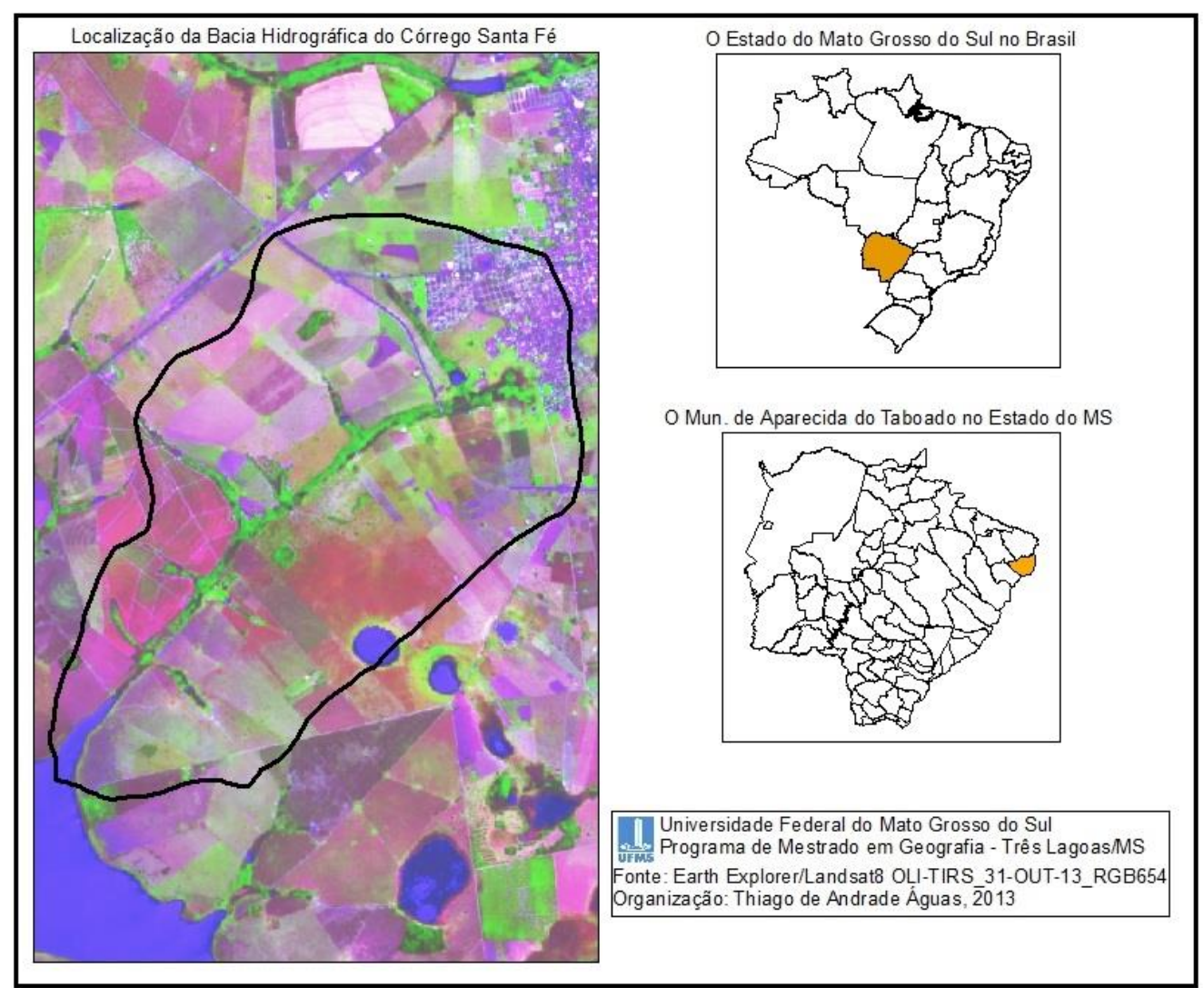

Org. ÁGUAS, 2013

O município de Aparecida do Taboado localiza-se na porção leste do Estado de Mato Grosso do Sul, região centro-oeste do Brasil, tem como limite os municípios de Paranaiba - MS, Inocencia - MS, Selviria - MS, Rubineia - SP e llha Solteira - SP.

\section{METODOLOGIA}

Para a realização dos mapas de fragilidade ambiental, foram elaboradas seis etapas a serem seguidas: 


\subsection{Primeira etapa}

Inicialmente, foram coletadas informações geográficas para a elaboração de um banco de dados em ambiente SIG. Foram obtidas imagens de Satélite LANDSAT 8 OLI/TIRS, do ano de 2013 órbita/ponto 223/74 e imagens do radar SRTM (Shuttle Radar TopographyMission), do ano de 2000. Para a seleção das imagens foram utilizados os critérios de disponibilidade gratuita das imagens e percentual de nuvens. Também foram utilizados os dados vetoriais disponibilizados no banco de dados do SISLA/IMASUL para editoração dos mapas de solo e áreas prioritárias

\subsection{Segunda etapa}

Os procedimentos operacionais para os processamentos dos dados orbitais, cadastrais e temáticos foram realizados em um ambiente de sistemas destinados à aquisição, armazenamento, manipulação, análise e apresentação de dados georreferenciados, ou seja, Sistema de Informação Geográfica (Ferreira, 2011)

Os shapes disponibilizados no SISLA/IMASUL deram subsídios para a elaboração dos mapas de solos e áreas prioritárias. As imagens LANDSAT8 OLI/TIRS serviram de base para a elaboração dos mapas de uso e ocupação da terra e a SRTM serviu como base para a elaboração do mapa de declividade. Já o mapa de pluviosidade, foi elaborado a partir dos dados de precipitação provenientes no site da CPAO.EMPRABA, aonde os mesmos foram inseridos em um arquivo shapefile (.shp) com sua estação e valor de precipitação em $\mathrm{mm}$ e interpolado pela ferramenta IDW, disponível no software ArcGIS®.

\subsection{Terceira etapa}

Com os mapas de solo, declividade, uso da terra, pluviosidade e áreas prioritárias prontas, foram reamostrados os seus respectivos valores de acordo com a metodologia de Ross (1994), variando os valores de 1 (muito fraco) a 5 (muito forte).

\subsection{Quarta etapa}

Com os valores refeitos conforme a metodologia de Ross (1994), foram sobrepostos os mapas de pluviosidade, solos, áreas prioritárias e declividade. Tal 
procedimento gerou o mapa de Potencial Ambiental da Bacia Hidrográfica do Córrego Santa Fé.

\subsection{Quinta etapa}

Posteriormente foi gerado o mapa de uso e ocupação da terra da área de estudo. Tal procedimento foi realizado no software Spring disponibilizado pelo INPE utilizando a ferramenta de classificação por pixel utilizando o critério de interpretação de imagens orbitais proposto por (FLORENZANO, 2008)

Após a geração de mapeamento de uso e ocupação da terra, correlacionouse o mapa de potencial ambiental ao mapa de uso e ocupação da terra gerando uma novo dado: mapa de fragilidade ambiental, conforme o objetivo almejado no artigo.

\section{RESULTADOS}

\subsection{Análises fiosigráficas.}

\subsubsection{Solos}

Na região da Bacia do Córrego Santa Fé encontram-se os seguintes solos: Latossolo Vermelho Escuro, Latossolo Roxo, Pedzolico Vermelho-Amarelo (Figura 2).

Figura 2: Mapa de solos da Bacia Hidrográfica do Córrego Santa Fé.

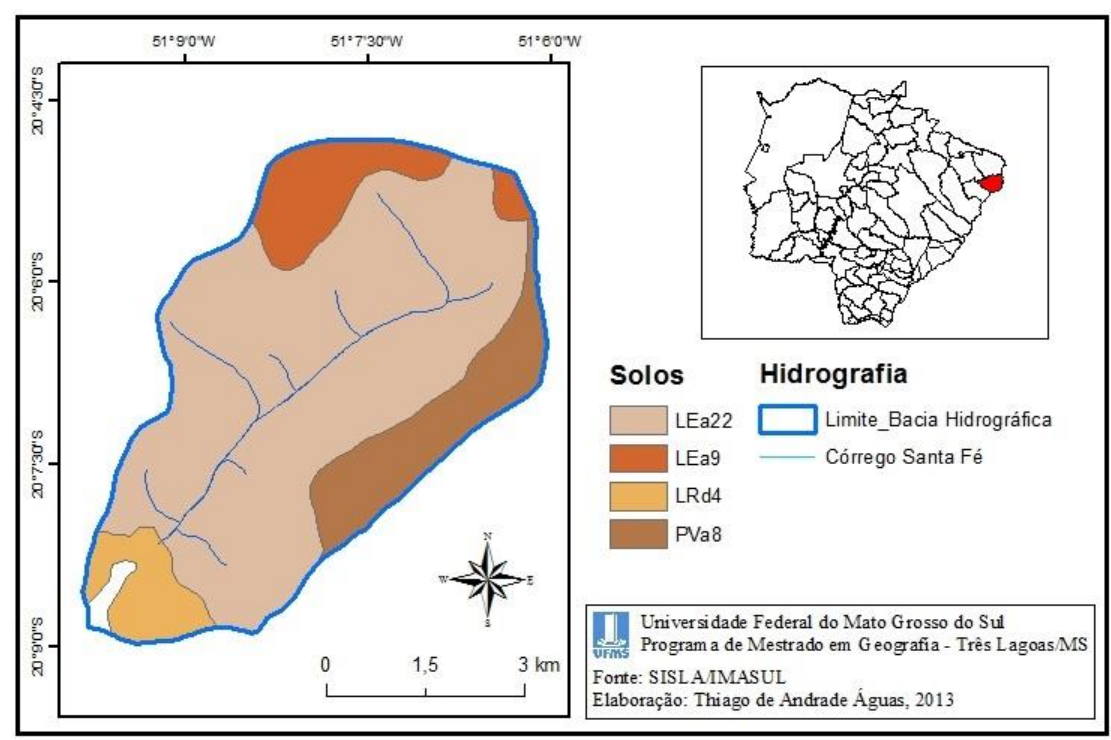

Org.: ÁGUAS, 2013 
Predomina-se na região da Bacia Hidrográfica o Solo Latossolo Vermelho Escuro de textura media e argilosa comum de relevos plano e suave ondulado, sendo encontrado em quase toda a região da bacia. Já na margem esquerda da bacia encontra-se uma região composta por solo Pedzolico Vermelho-Amarelo, de textura media muito cascalhenta e também de relevo suave ondulado e nas duas margens do Córrego Santa Fé. Já nas proximidades da foz, foram encontradas manchas identificadas como Latossolo Roxo de textura muito argilosa e relevo suavemente ondulado.

\subsubsection{Pluviosidade}

Constatou-se que os dados que determinaram os índices de precipitação, média total anual e mensal, indicam que o Córrego Santa Fé, recebe os maiores índices de precipitação no seu baixo curso (Figura 3) com valores médios de $1.196 \mathrm{~mm}$. A nascente apresenta valores médios anuais $1.192 \mathrm{~mm}$ e o médio curso os índices são de $1.193 \mathrm{~mm}$. Com relação a tais índices concentrados no médio e baixo curso, é viável destacar que o Córrego Santa Fé está sendo abastecido de forma mais intensa em sua foz. No alto curso (nascente) foram verificados os menores índices de precipitação, conforme a Figura 3.

Figura 3: Mapade Pluviosidade da Bacia Hidrográfica do Córrego Santa Fé

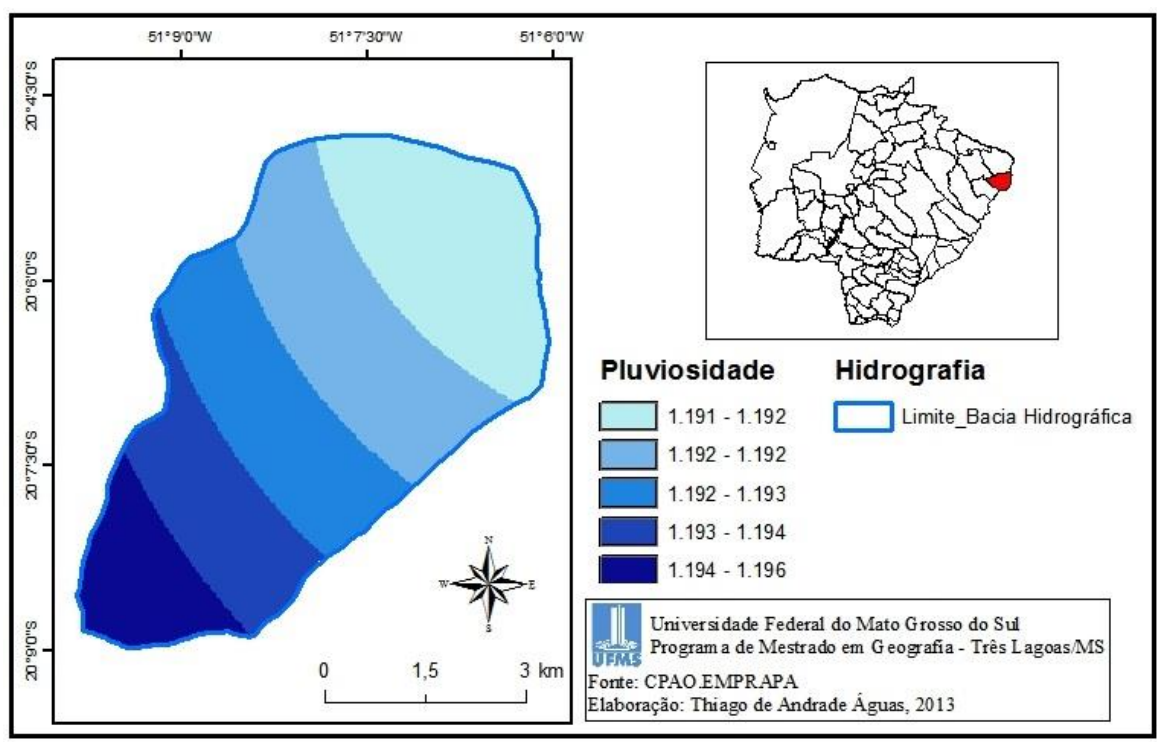

Org. ÁGUAS, 2013 


\subsection{3 Áreas Prioritárias}

Os dados encontrados na Bacia Hidrográfica do Córrego Santa Fé não oferecem riscos à diversidade biológica, no mapa toda a área é indica como não prioritárias.

Figura 4: Mapa de Pluviosidade da Bacia Hidrográfica do Córrego Santa Fé.

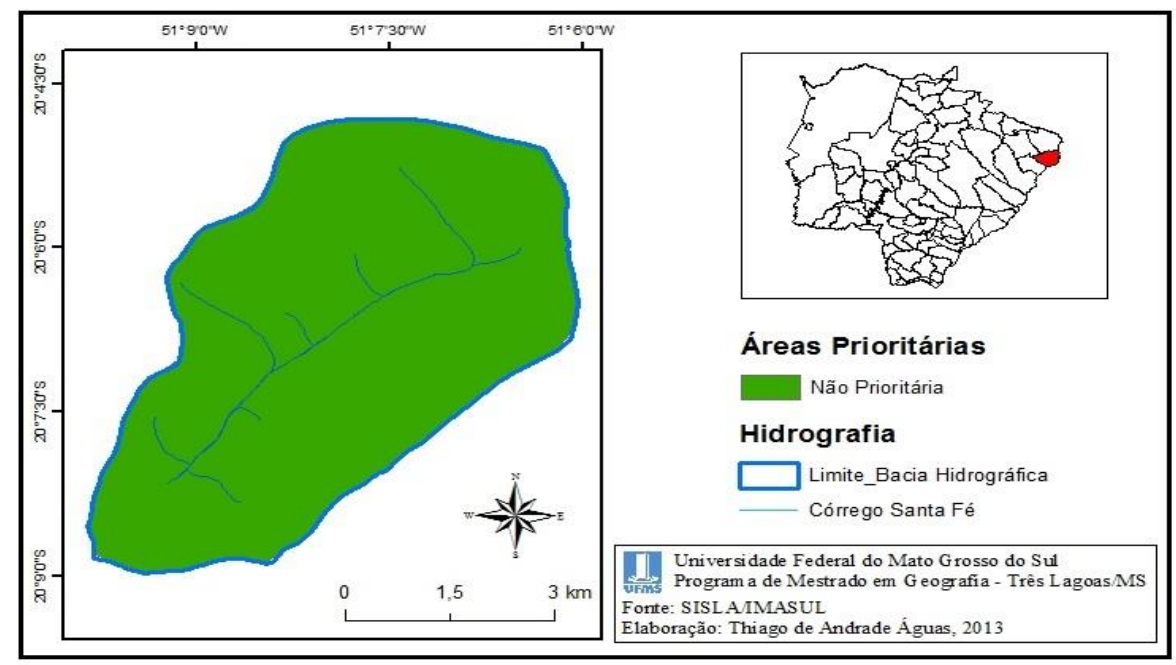

Org. ÁGUAS, 2013

\subsubsection{Declividade}

Os índices clinográficos indicaram que o Córrego Santa Fé apresenta como característica, relevo bastante aplainado, com maior representatividade de declive a classe de $0-2 \%$ e à classe de 2 á $4 \%$. Os valores com maior representatividade, no mapeamento, é a classe de 0 á $2 \%$, indicando realmente o baixo índice de elevação no Córrego Santa Fé.(Figura 5).

Figura 5: Mapa de Declividade da Bacia Hidrográfica do Córrego Santa Fé

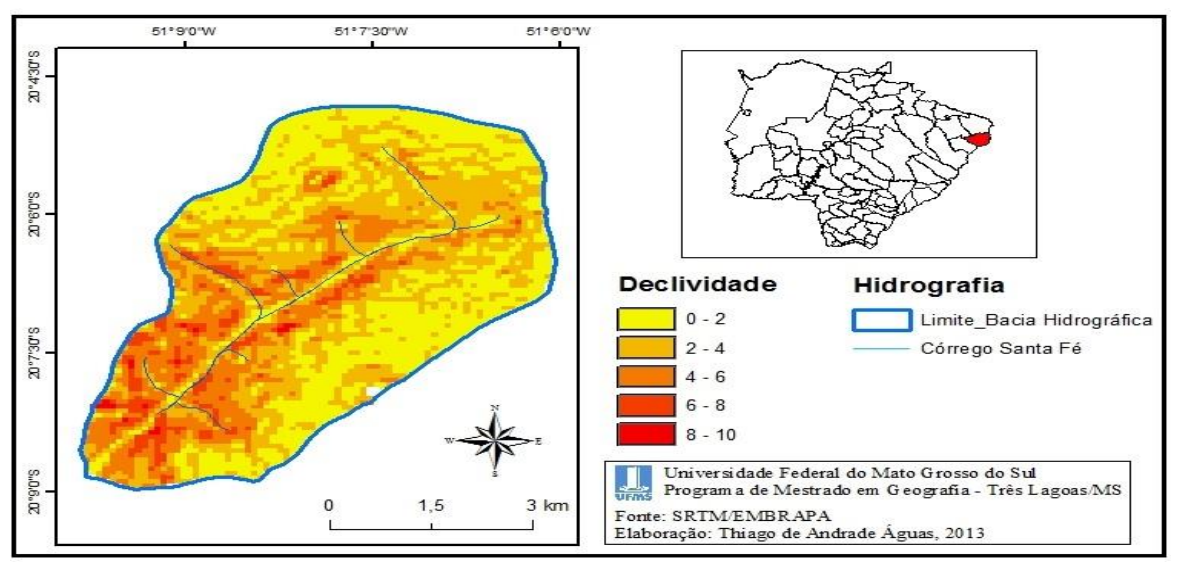

Org. ÁGUAS, 2013 


\subsection{Uso e ocupação da terra}

O levantamento do uso e ocupação da terra tornou-se um importante elemento para o entendimento dos padrões de organização do espaço geográfico, pois o dado mais atualizado sobre uma determinada área auxiliará, dentre outros, identificar e localizar os agentes responsáveis pelas suas condições ambientais. E seja qual for a sua forma de utilização dificilmente permanecerá inalterado. Por isso, a necessidade cada vez maior da atualização constante de registro da superfície terrestre para que seus resultados possam ser analisados (LOCH, 1984).

No entanto Mendonça (1997) ressalta que conhecer o uso e ocupação da terra, consiste em fornecer subsídios ao planejamento para a ordenação do espaço físico e a previsão dos elementos relativos às necessidades humanas, de modo a garantir um meio ambiente que proporcione qualidade de vida a seus habitantes. Deste modo percebe-se que os estudos de uso da terra se tornaram importante no contexto histórico atual, uma vez que os assuntos relacionados à questão ambiental têm sido cada vez mais discutidos.

O produto desta etapa resultou-se em mapas de uso da terra da Bacia Hidrográfica do Córrego Santa Fé, utilizou-se o Software SPRING - 5.2.4, na qual se criou uma "categoria temática" e logo se foram criadas as seguintes classes: Malha Urbana, Vegetação, Cana de Açúca, Pastagem e Água (Figura 6).

Figura 6: Mapa de Uso e Ocupação da Terra da Bacia Hidrográfica do Córrego Santa Fé

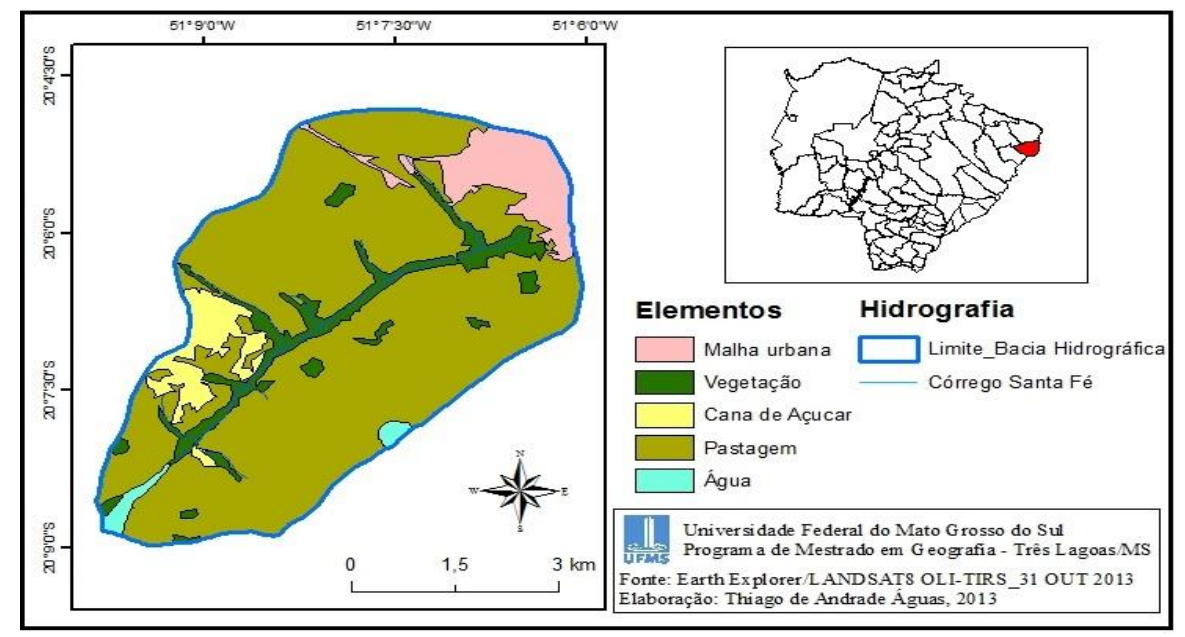

Org. ÁGUAS, 2013 
A analise do uso e ocupação da terra no ano de 2013 apresenta um resumo geral sobre a paisagem na Bacia Hidrográfica do Córrego Santa Fé, permitindo afirmar o predomínio do uso de pastagem em toda área da bacia atingindo cerca de $78 \%$ da área total da bacia.

Figura 7: Pastagem.

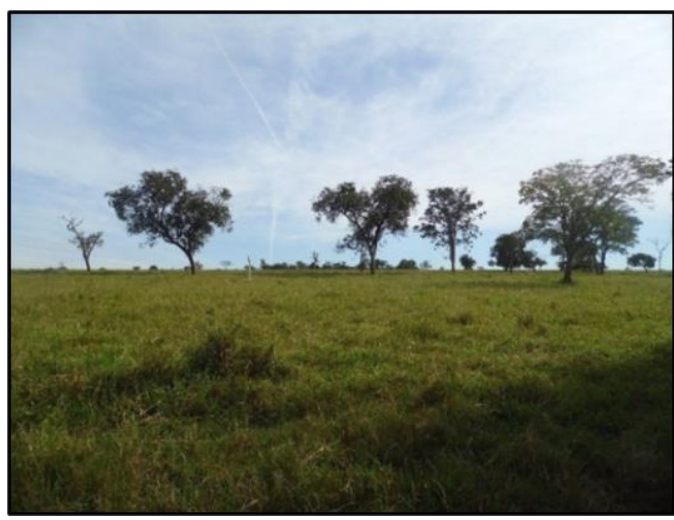

Fonte: LIMA, 2013
Figura 8: Pastagem.

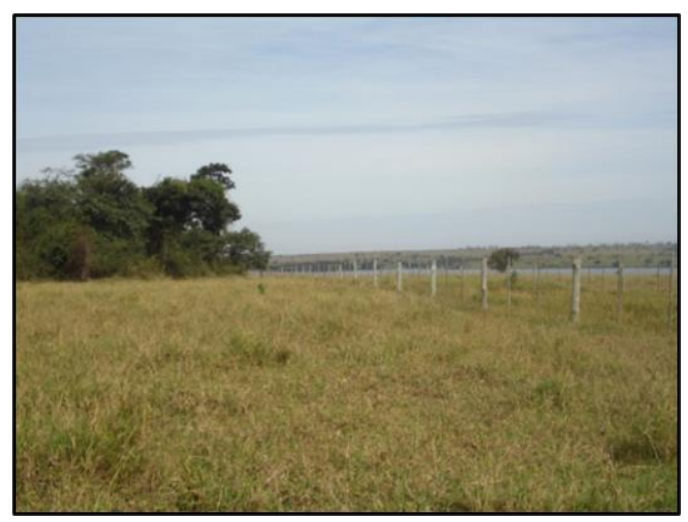

Fonte: LIMA, 2013.

A classe cana de açúcar apresenta-se em pequena proporção com $5 \%$ da área da Bacia do Córrego Santa Fé, a classe cultura temporária é representada principalmente por cana.

Figura 9: Cana de açúcar.

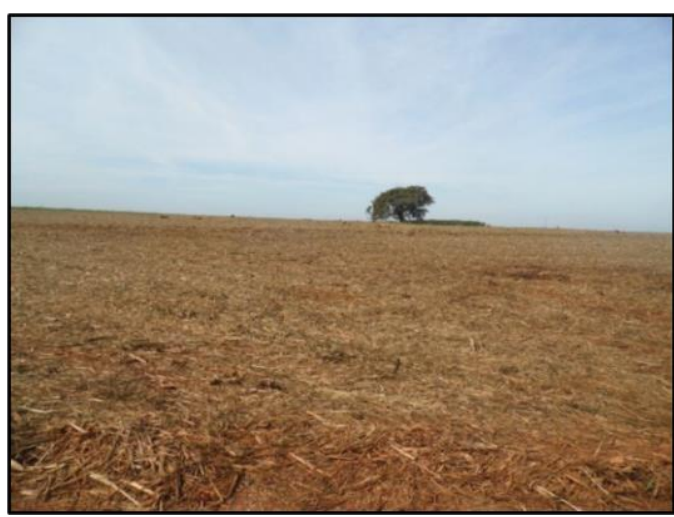

Fonte: LIMA, 2013
Figura 10: Cana de açúcar.

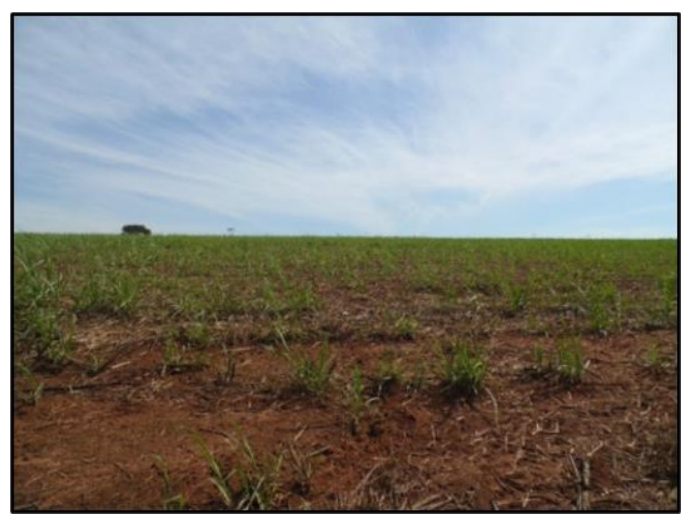

Fonte: LIMA, 2013.

Em seguida a classe vegetação é do tipo arbóreo denso e aberta, ocupando apenas $8 \%$ da área total. (Figura) 
Figura 11: Vegetação.

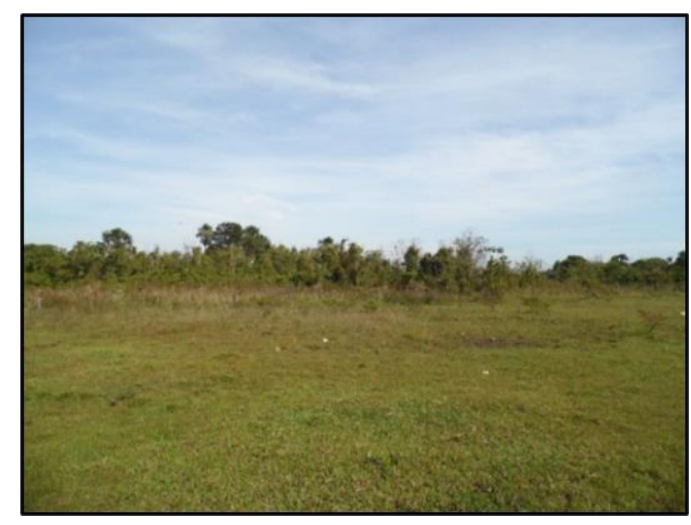

Fonte: LIMA, 2013
Figura 12: Vegetação.

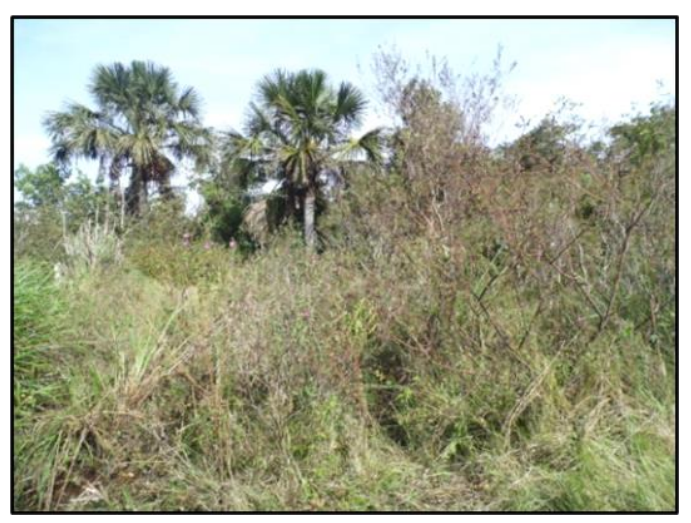

Fonte: LIMA, 2013.

A classe malha urbana aparece com a mesma porcentagem da classe vegetação, com 8 \% da área total da bacia.

Outra classe de pequena proporção denominada hidrográfica representa $1 \%$ da área, os mesmos podem ser influenciados sofrendo variações, pois estão muitas vezes ligados a períodos chuvosos ou dias posteriores a grandes precipitações em que o satélite esteja mapeando a superfície terrestre.

Figura 13: Hidrografia.

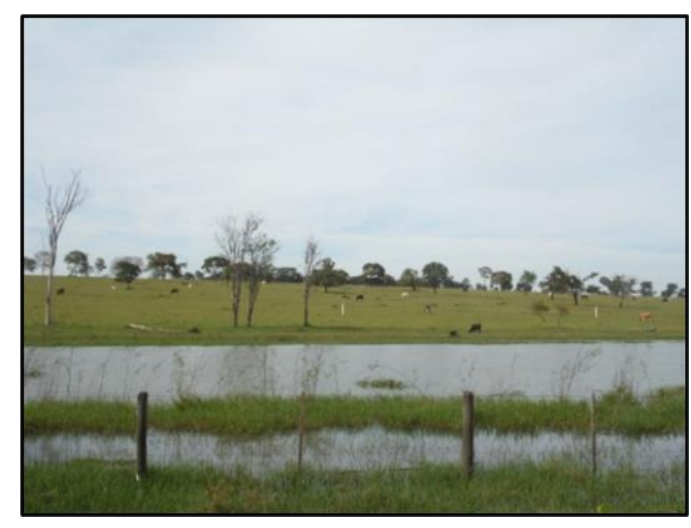

Fonte: LIMA, 2013
Figura 14: Hidrografia.

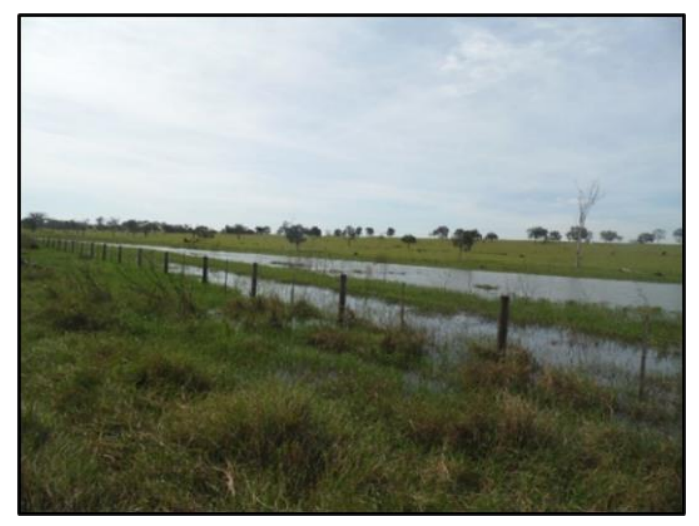

Fonte: LIMA, 2013.

Desse modo, é importante lembrar que os sistemas atmosféricos possuem grandes influencia nos resultados das imagens de satélite (FERNANDES, 2013). 


\subsection{Potencial Ambiental}

O Mapeamento da Bacia Hidrografica do Corrego Santa Fé, possibilitou observar que existe um equilíbrio dinâmico entre as partes naturais (solo, pluviosidade, áreas prioritárias e declividade), tendo em vista o resultado apresentado no mapa variando entre as classes 1 (muito fraca) e 2 (fraca), conforme a Figura 17.

Figura 15: Mapa de Fragilidade Potencial da Bacia Hidrográfica do Córrego Santa Fé

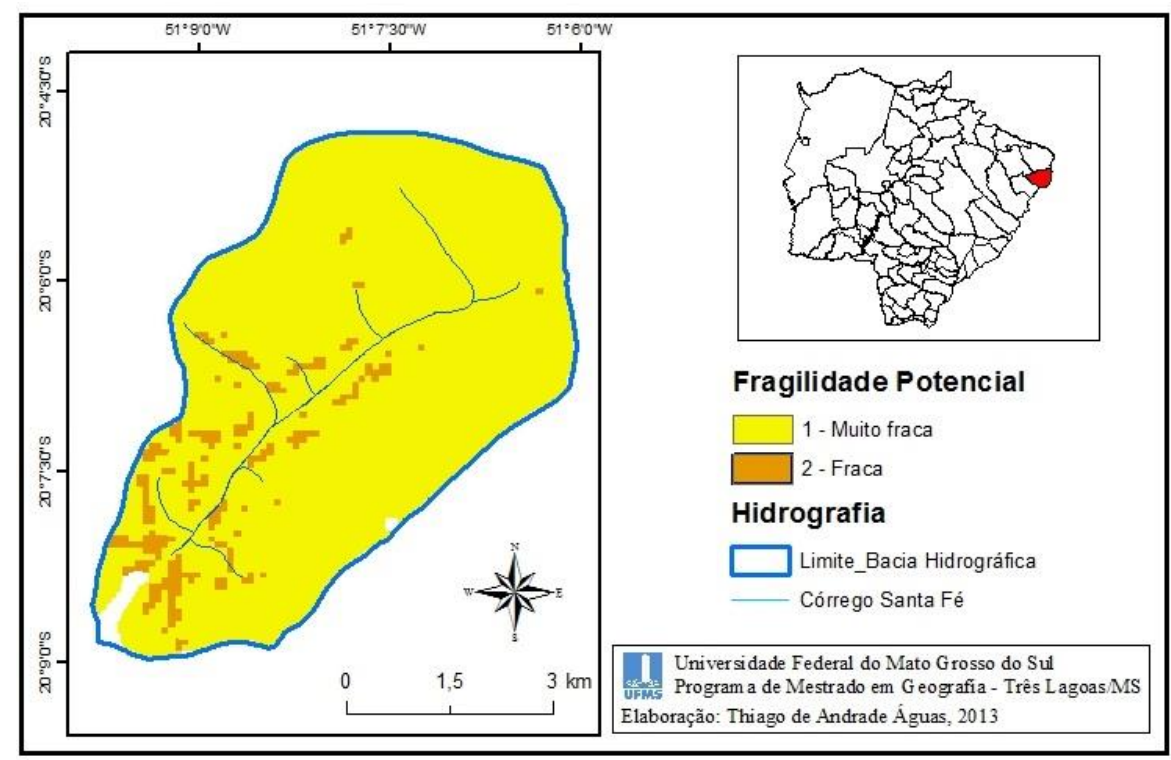

Org. ÁGUAS, 2013

As classes de muito fraca fragilidade potencial e fraca fragilidade potencial são locais onde normalmente se verifica maior equilíbrio entre os componentes naturais.

\subsection{Fragilidade Ambiental}

Segundo Ross (1994), deve-se entender a dinâmica e funcionamento dos ambientes naturais com ou sem intervenção humana. Desta forma a elaboração do zoneamento ambiental é produto do desenvolvimento de uma metodologia que visa a dinâmica do ambiente natural e do meio sócio econômico, buscando a integração e interdisciplinaridade das áreas que diz respeito à realidade.

A figura $18 \mathrm{diz}$ respeito ao que Ross (1194), denomina em sua metodologia como fragilidade ambiental. Nela foram sobrepostos os mapas de solo, uso da terra, 
declividade, pluviosidade e áreas prioritárias gerando o mapa da Bacia Hidrográfica do Córrego Santa Fé.

Figura 16: Mapa de Fragilidade Ambiental da Bacia Hidrográfica do Córrego Santa Fé.

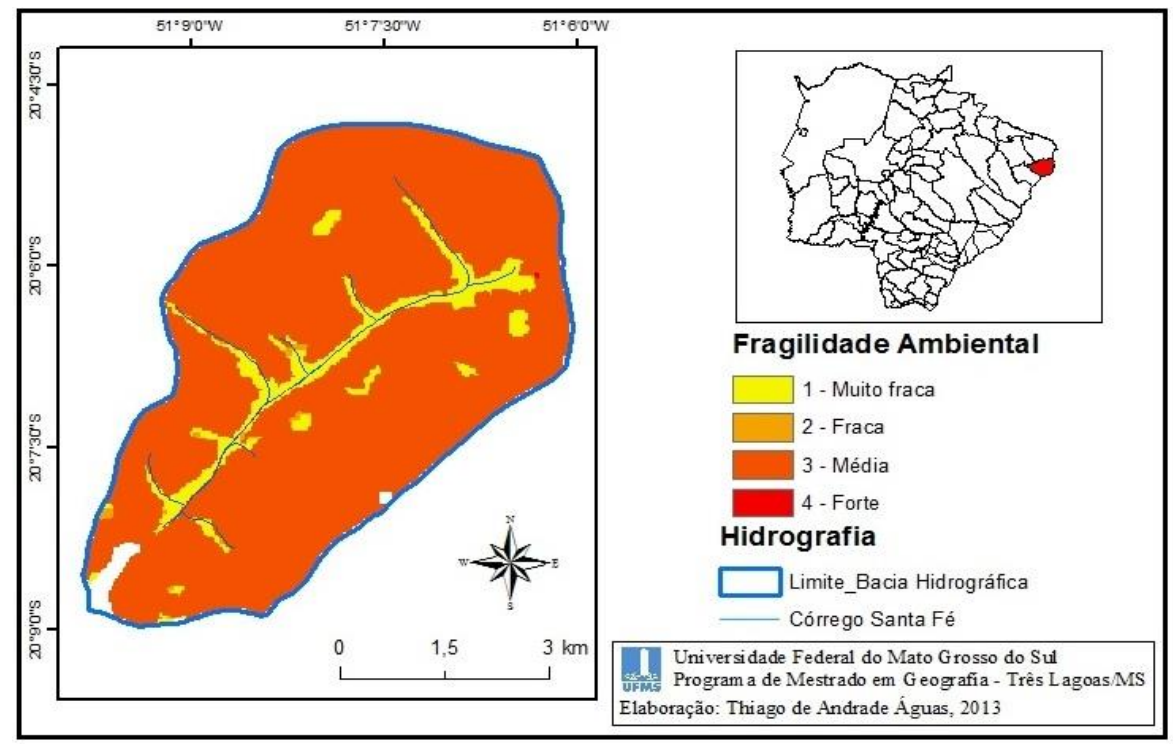

Org. ÁGUAS, 2013

O que pode ser observado são áreas homogêneas tendendo a fragilidade de valor médio. Apesar do mapa de fragilidade potencial não apresentar valores altos, o uso intensivo expôs a área da bacia a maiores riscos, sanando apenas as áreas de preservação permanente, conforme é exigido por lei para proteção dos mananciais.

A interferência antrópica com o uso intensivo do solo com a cana e a pastagem como visto na figura 6 , gerou interferência no equilíbrio da região. A predominância da classe media de fragilidade ambiental é consequência do uso intensivo e do uso desordenado do uso da bacia, gerando áreas suscetíveis a problemas ambientais.

\section{CONSIDERAÇÕES FINAIS}

Com relação ao trabalho observou se que os maiores índices de precipitação se concentram no baixo curso, associados aos solos latossolo roxo e ao latassolo vermelho escuro. Em relação às áreas prioritárias as mesmas não oferecem riscos a diversidade biológica local. Com relação a fragilidade potencial ambiental o mapa gerado indicou que a área está em equilíbrio entre as partes naturais, sendo 
possível observar que as áreas são menos susceptíveis a degradação. Contudo, mapa de fragilidade ambiental, foi inserida aos componentes naturais a interferência antrópicas com o uso intensivo da terra, gerando instabilidade no equilíbrio da bacia. No mapa, predomina-se a classe média de fragilidade ambiental como resultado do uso da terra, gerando possíveis problemas ambientais. A metodologia de fragilidade ambiental teve resultados positivos perante os dados apresentados para análise ambiental. Apesar de constituir um estudo multidisciplinar, supriu como esperado a análise, tanto orbital como em campo, do déficit do ordenamento do território perante a bacia hidrográfica do córrego Santa Fé.

\section{BIBLIOGRAFIA}

BACANI, V. M. Geotecnologias aplicadas ao ordenamento físico-territorial da bacia do alto rio Coxim, MS. 2010. Tese (Doutorado em Geografia Física). Universidade de São Paulo, São Paulo, 2010.

CAMARGO, M. U. C. Os Sistemas de informações geográficas (S.I.G.) como instrumento de gestão em saneamento. Rio de Janeiro : ABES, 1997.

CREPANI, E.; MEDEIROS, J.S.; AZEVEDO, L.G.; DUARTE, V.; HERNANDEZ, P. \& FLORENZANO, T. Curso de Sensoriamento Remoto Aplicado ao Zoneamento Ecológico-Econômico. São José dos Campos: INPE, 1996.

CREPANI, E.; MEDEIROS, J. S.; FILHO, P. H.; FLORENZANO, T. G.; DUARTE, V. BARBOSA, C. C. F. Sensoriamento Remoto e Geoprocessamento Aplicados ao Zoneamento Ecológico Econômico e ao Ordenamento Territorial. São José dos Campos: SAE/INPE, 2001.

CREPANI, E.; MEDEIROS, J.S.; AZEVEDO, L.G.;DUARTE, V.; HERNANDEZ, P.; FLORENZANO, T \& BARBOSA, C. Sensoriamento Remoto e Geoprocessamento Aplicados ao Zoneamento Ecológico- Econômico e ao Ordenamento Territorial. São José dos Campos: INPE, 2000.

EMPRESA BRASILEIRA DE PESQUISA AGROPECUÁRIA - EMBRAPA. Sistema Brasileiro de Classificação de Solos. Brasília: Serviço de Produção de Informação, 2009.

FERREIRA, C. C. Geotecnologias aplicadas à criação e organização de banco de dados geoambientais da Bacia Hidrográfica do Rio Sucuriú - MS/BR. Dissertação (Mestrado em Geografia) - UFMS/CPTL, Três Lagoas, 2011

FLORENZANO, T. G., Imagens de satélite para estudos ambientais. São Paulo. Oficina de Textos, 2008.

FREIRE, J. T. A gestão local de riscos e a vulnerabilidade no município petrolífero de Madre de Deus./Jamile Trindade Freire, 2011. 175 f.: il.

$\mathrm{LOCH}, \mathrm{C}$. Noções básicas para a interpretação de imagens aéreas, bem como algumas de suas aplicações nos campos profissionais. Ed da UFSC. Florianópolis, 1984.

MENDONÇA, F. et al. O espaço geográfico em análise. In: RA'E GA. v.1 Curitiba: Departamento de Geografia/UFPR, 1997.

MIRANDOLA - AVELINO, P. H. Análise Geo - Ambiental Multitemporal para fins de Planejamento Ambiental: Um exemplo aplicado à Bacia Hidrográfica do Rio Cabaçal Mato Grosso - Brasil. 
Tese de Doutorado em Geografia do Programa de Pós Graduação em Geografia da Universidade Federal do Rio de Janeiro, 2006,317 páginas.

ROSS, J. L. S. "Análise Empírica da Fragilidade dos Ambientes Naturais e Antropizados". In: Revista do Departamento de Geografia n8, FFLCH-USP, São Paulo, 1994.

ROSS, J. L. S. "Análise e Síntese na Abordagem Geográfica da Pesquisa para o Planejamento Ambiental”. In: Revista do Departamento de Geografia n`9, FFLCH-USP, São Paulo, 1995.

SANTOS, R. F. dos. Planejamento Ambiental: teoria e prática. São Paulo: Oficina de textos, 2004.

ROSS, J. L. S. "O Registro Cartográfico dos Fatos Geomórficos e a Questão da Taxonomia do Relevo". In: Revista do Departamento de Geografia - FFLCH-USP, n 6, São Paulo, 1992.

SARAIVA, J. A. P. Baía de todos os santos: vulnerabilidades e ameaças/. José Augusto Peixoto Saraiva. - Salvador, 2008. 191 f. : il. Collor. 